Jaramillo-García, Ó.A. (2018). Gramáticas sociales en los márgenes: formas de gobierno de la vida en el barrio Las Brisas de la ciudad de Pereira. Revista de Antropología y Sociología: VIRAJES, 20 (1), 149-174. DOI: 10.17151/rasv.2018.20.1.8

\title{
GRAMÁTICAS SOCIALES EN LOS MÁRGENES: FORMAS DE GOBIERNO DE LA VIDA EN EL BARRIO LAS BRISAS DE LA CIUDAD DE PEREIRA
}

\section{ÓSCAR ARMANDO JARAMILLO-GARCÍA*}

Recibido: 10 de octubre de 2017

Aprobado: 15 de diciembre de 2017

Artículo de Investigación

* Candidato a Doctor en Ciencias Sociales, Niñez y Juventud. Docente Universidad de Manizales, Manizales, Colombia. Fundación Universitaria del Área Andina, Pereira, Colombia. E-mail: Ojaramillo@umanizales.edu.co. (D) ORCID: 0000-0002-6580-7847.Google Scholan 


\title{
Resumen
}

Objetivo. Dar cuenta de las dinámicas que conducen a ciertas formas de gobierno de la población del barrio las Brisas de la ciudad de Pereira. Metodología. El diseño metodológico se construye desde una composición que pone en diálogo pistas de la genealogía foucaultiana con el análisis estructural de contenido de Hiernaux. Resultados y conclusiones. A partir de la metodología se da paso a una analítica que va a mostrar cuatro formas de desciudadanización en medio de estos códigos complejos: una de ellas tiene que ver con el abandono del Estado; la segunda es infringida por las reglas sociales que impone la paralegalidad de una banda criminal del sector; la tercera aparece por la pertenencia a esta banda y la excepción que se genera para convertir a dichos sujetos en blancos y la cuarta aparece por los daños colaterales que puede generar el uso de la fuerza contra blancos legítimos.

Palabras clave: gobierno, gramática, sistema social, ciudadanía.

\section{THE MARGINS OF SOCIAL GRAMMARS: FORMS OF GOVERNMENT OF LIFE IN THE LAS BRISAS NEIGHBORHOOD OF THE CITY OF PEREIRA}

\begin{abstract}
Objective. To give an account of the dynamics that lead to certain forms of government of the population in Las Brisas neighborhood in the city of Pereira. Methodology. The methodological design is constructed from a composition that puts in dialogue tips of the Foucauldian genealogy with Hiernaux's structural analysis of content. Results and conclusions. Based on the methodology, the way is prepared for an analytical approach that will show four forms to decitizenize in the midst of these complex codes: the first one dealing with the abandonment of the State; the second is inflicted by the social rules imposed by the paralegal of a criminal gang in the sector; the third appears by belonging to this gang and the exception that is generated to convert said subjects into objectives; and the fourth appears because of the collateral damages that the use of force against legitimate targets may generate.
\end{abstract}

Key words: government, grammar, social system, citizenship. 
$\square \mathrm{n}$ este artículo se despliega una lectura enfocada fundamentalmente desde el lente postestructuralista de un sector popular de la ciudad de Pereira, el cual es particular dadas sus condiciones sociales complejas. La vida de un barrio de comuna con no más de 17 años, pero con una historia reconocida en la ciudad por su precariedad y exclusión. Se analiza la producción de ciertas condiciones de posibilidad (Foucault, 2006) que dan lugar a la emergencia de prácticas que se configuran en un régimen aglutinador, que aquí se denomina gramática social (Jaramillo, 2017). Dicha gramática muestra la manera en que los modos de gobierno de la vida (Foucault, 1999) dan paso a espacios sociales concretos y localizados que cobran su forma dependiendo de los ejercicios de poder que se impliquen en su producción. Por esta razón se hace este abordaje desde una clave de lectura del gobierno de unos hombres sobre otros (Foucault, 2006, 2008; Sáenz, 2014; Grinberg, 2008; Castro-Gómez, 2010) ${ }^{1}$. Por tal motivo se quiere ver como para el caso de este espacio social emergen elementos ligados a maneras bio(tanato)políticas (Mendiola, 2009), desde la regulación de la población, en tanto diseños zonificados (Mbembe, 2011), y tácticas que van sobre las tasas de natalidad, morbilidad y mortalidad. Así, en medio de una tensión con el abandono (Agamben, 2013), se ligan a una cierta política de la muerte calculada por las maneras de gobierno de la pobreza en este sector. Al momento, esto se conecta a actores como "bandas criminales" que reconfiguran las reglas de juego de este medio artificial (Foucault, 2006) a través de parámetros de paralegalidad (Reguillo, 2010). Lo que permite visibilizar como las gramáticas sociales de este sector generan formas de desciudadanización (Urteaga y Moreno, 2015), es decir escenarios de peligros letales para la vida, en tanto perdida de garantías de derecho y protecciones del Estado.

\section{Horizonte categorial: la sociedad de control y el establecimiento del milieu}

Deleuze (1995) propone que las sociedades disciplinarias se hallan en crisis y que el control sobre los sujetos ahora se da al aire libre, en donde se ejerce un automoldeado deformante que cambia constantemente como un tamiz cuya maya varía en cada punto.

\footnotetext{
${ }^{1}$ No se quiere decir que en este escenario social no existan modos de resistencia, agenciamientos colectivos, que quieren transformar y no dejarse gobernar totalmente por este tipo de condiciones; no obstante, ello no es el foco de discusión de este artículo.
} 
Estos elementos deleuzianos de la sociedad de control se producen en medio de una gubernamentalidad que deja hacer, deja pasar -laissez faire, laissez passer-, teniendo un par de connotaciones importantes (Foucault, 2006, 2008; Deleuze, 1995). La primera que no es una sociedad de normación, como la disciplinaria donde la norma se encuentra establecida a priori antes de que sucedan los eventos, sino que es una sociedad de normalización donde las normas se generan en medio del despliegue de los eventos —o al final según tasas estadísticas_ que permiten una regulación flexible y al tiempo ciertos márgenes, no muy amplios, de anormalidad que pueden ser tolerados (Foucault, 2006). De esta manera se deja que ciertas cuestiones sociales - sobre todo las que atañen a lo económico, pero también algunas de las que conciernen a la vida de la población - se desenvuelvan libremente, es decir sin la mayor regulación del Estado mientras ello no sea indispensable, con un Estado de corte neoliberal que asume cada vez menos responsabilidades en el pacto social.

Posteriormente no se puede perder de vista que en las sociedades de control se piensan las relaciones de poder como juegos estratégicos entre libertades entendidas como tecnologías de gobierno, pero también como búsqueda de grados de libertad y de formas de resistencia donde el poder es una acción sobre acciones posibles que pueden ser revertidas (Foucault, 1988). Entonces ya no hay un solo accionar anatomopolítico, sino que se actúa sobre la acción del individuo entendida en estos términos: "el individuo no es el origen absoluto de la acción; por consiguiente, se interviene sobre toda una serie de elementos que determinan la acción" (Lazzarato, 2007, p. 90). A este tenor, hay un campo de acciones posibles. $Y$ es en este campo que entra a jugar el ejercicio del poder para constituir un ámbito que permita que la acción sea coherente o idónea para el tipo de intereses de la racionalidad neoliberal de corte empresarial. Si se tiene en cuenta que el tipo de contorno que se constituye busca dar con la captura y normalización de la multiplicidad de acciones inconvenientes que quieren ser delimitadas y gubernamentadas. Habrá que proponer, pues, desde el marco foucaultiano, el concepto de milieu: que se hace tan importante para pensar la forma en que se construye un espacio que permite circular a unos dispositivos de gobierno que operan sobre las conductas de los sujetos. Así, en este sentido, esta gubernamentalidad,

tratará de acondicionar un medio en función de acontecimientos o de series de acontecimientos o elementos posibles, remite a lo temporal o a lo aleatorio, una temporalidad y una aleatoriedad que habrá que inscribir en un espacio dado [...]. El medio [...] es lo necesario para explicar la acción a distancia de un cuerpo sobre otro. 
Se trata, por lo tanto, del soporte y el elemento de circulación de una acción. (Foucault, 2006, p. 40-41)

Aquí puede afirmarse que las técnicas de control están interesadas en generar aquel marco que les dé como estrategia la posibilidad de actuar no sobre el juego mismo sino sobre las reglas de juego, extendiendo de esta manera su capacidad de acción. Ya no es una acción en un juego sobre un sujeto dado, sino que es un accionar como medio ambiente sobre todo lo que sucede dentro de él; una forma de buscar la autorregulación de la población. Por tanto, puede comprenderse el medio como "el ámbito en el que se da la circulación, al momento que esa cantidad de efectos masivos que afectan a quienes residen en él"' (Foucault, 2006, p. 40).

\section{Diseño metodológico}

El presente escrito propone un diseño de método compuesto, que permite un abordaje analítico en clave de ontología crítica (Foucault, 2003) y que versa como unidad de análisis sobre las prácticas (Veyne, 1984; Castro-Gómez, 2010) para visibilizar procesos de producción de lo social. De esta forma se establece un diálogo entre líneas fuerza de algunas clave metódicas foucaultianas (Foucault, 1985, 1994, 2002, 2003, 2006, 2008, 2009), fundamentalmente las llamadas genealógicas, y el análisis estructural de contenido que emerge desde la propuesta e influencias de Hiernaux (Hiernaux et Ganty, 1977; Hiernaux, 2008; Suárez, 2008; Saldarriaga, 2003, 2008; Saldarriaga, 2015).

En esta composición de método se trabaja desde lo genealógico, una categoría que se codifica como gramática social (Veyne, 1984; CastroGómez, 2010) que no es más que los códigos entendidos como sistemas de reglas que hacen que lo múltiple devenga regularidad en un momento y lugar histórico particular. Con ello se comprende lo múltiple como las diferentes posibilidades que tienen sociedades y sujetos de estructurarse y constituirse bajo regularidades que permiten dar forma a campos y juegos con reglas contingentes, pero de alguna duración, que marcan en gran medida la dinámica de su cotidianidad. Se anota que las mismas están atravesadas fundamentalmente por relaciones de poder-saber y gobiernoverdad (Foucault, 2003) en medio de la administración y gestión de la vida (Castro-Gómez, 2009).

Ahora bien, del análisis estructural de contenido, se usan los principios de la descripción estructural: la disyunción, la asociación, la isotopía y la condensación descriptiva (Hiernaux, 2008; Suárez, 2008; Saldarriaga, 2008; Saldarriaga, 2015). En este contexto decir disyunción contradefinición 
o distinción (que se gráfica: / ) es referir aquello que permite al interior de un mismo género (totalidad) identificar ciertas cosas como existentes y específicas, unas en relación con otras; es decir dos términos opuestos entre sí que constituyen una totalidad donde $\mathrm{A}+\mathrm{B}=\mathrm{T}$ caliente/frío=temperatura (Hiernaux, 2008; Suárez, 2008). Otro de los principios básicos es el de la asociación o conjunción (que se gráfica: ê), el cual pone los elementos ya identificados por las disyunciones en relación con otros elementos salidos a la vez de otras disyunciones, formando así la red y los atributos de todos ellos (Hiernaux, 2008). Luego de estos puntos se convoca a la isotopía como un tercer principio básico que pone de manifiesto que el orden de las estructuras que transitan por el material, no responden al orden narrativo del mismo. De tal modo que aquellas "informaciones acerca de un conjunto de unidades de sentido que se articulan entre ellas, que forman "un lugar estructural común" se pueden hallar dispersas en diversos lugares del material" (Hiernaux, 2008, p. 95). El cuarto punto, en tanto que principio básico que se trae a colación, es la condensación descriptiva; este elemento alude a la diversidad de posibilidades con que cuenta el lenguaje, lo que hace que en un mismo corpus puedan encontrarse múltiples formas de aludir al mismo sentido: el caso de los sinónimos, metáforas, ejemplos o formulaciones que el investigador propone y recoge sintéticamente diversos sentidos que yacen en los datos.

De modo adicional la unidad de análisis, entendida como escenario social amplio, se refiere al barrio las Brisas (el cual tiene 17 años, ubicado en la comuna Villa Santana de la ciudad de Pereira). El barrio cuenta con 31 manzanas de viviendas de interés social con habitantes que tienen diversas procedencias (algunos provienen de una reubicación de la galería de la ciudad por reformas urbanísticas, otros son desplazados por la violencia y la pobreza con orígenes étnicos indígenas, afros y mestizos y otros reinsertados de grupos armados). Para configurar la unidad de trabajo se usó el muestreo por interés desde los criterios de adecuación, significatividad, suficiencia, pertinencia y accesibilidad (Bonilla-Castro y Rodríguez, 2005; Delgado y Gutiérrez, 1999), sumado al muestreo teórico (Strauus y Corbin, 2002), con el fin de orientar la recolección de la información luego de la obtención de los primeros datos y dar lugar a categorías emergentes; así se trabajó con 11 personas, 5 de género femenino y 6 de género masculino que habitan o trabajan en el barrio. Finalmente se toma la decisión de usar para la recolección de la información algo que se ha dado en llamar discursos sobre los modos de existencia (Jaramillo, 2017), que se conectan por la entrevista con un guion (Valles, 1999) y al tiempo abren paso a la construcción de un juego de fuentes no orales. 


\section{Resultados y discusión. Análisis de la información, gramáticas sociales en territorios menores: entre exclusión, gestión de la vida, neo-soberanía y nuda vida}

\section{Mecanismos de exclusión}

Las Brisas es un barrio pensado dentro de un diseño biopolítico específico (Foucault, 2006) como una estrategia para poner en la periferia poblaciones que se consideraban como peligrosas, es decir aquellos que habitaban a finales de la década de los 90 la galería del centro de la ciudad de Pereira, habitantes de calle, personas con conductas adictivas. Así lo afirma una de las participantes: "uno tiene que imaginarse Las Brisas como un barrio que fue pensado, como un espacio de segregación especial, un espacio alejado donde habitan, y en su tiempo habitaron, muchas de las personas de aquí de la plazoleta del Victoria" (P.F.1)2. Lo anterior, se recoge en un par de imágenes ${ }^{3}$ donde se indica con un círculo rojo la ubicación del barrio en el mapa de la ciudad de Pereira y se usan dos fotografías para mostrar sus características.

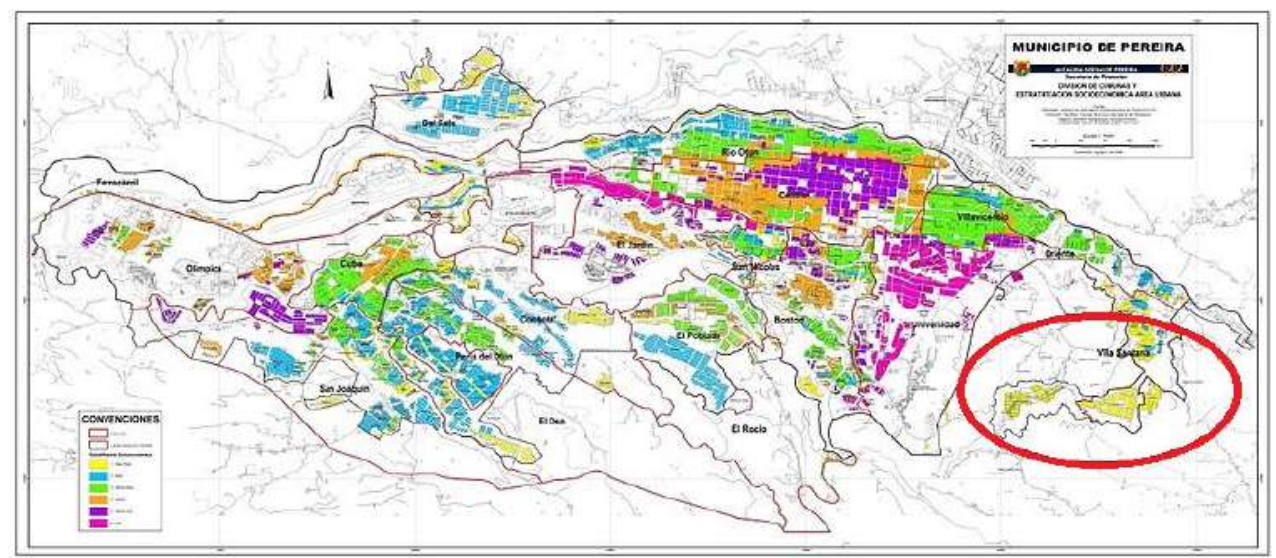

\footnotetext{
${ }^{2}$ Los códigos para nombrar los participantes en este análisis serán los siguientes: P.F. para participantes femeninas y P.M. para participantes masculinos seguidos de un número.

${ }^{3}$ Estas imágenes fueron compartidas por los participantes en una de las entrevistas.
} 

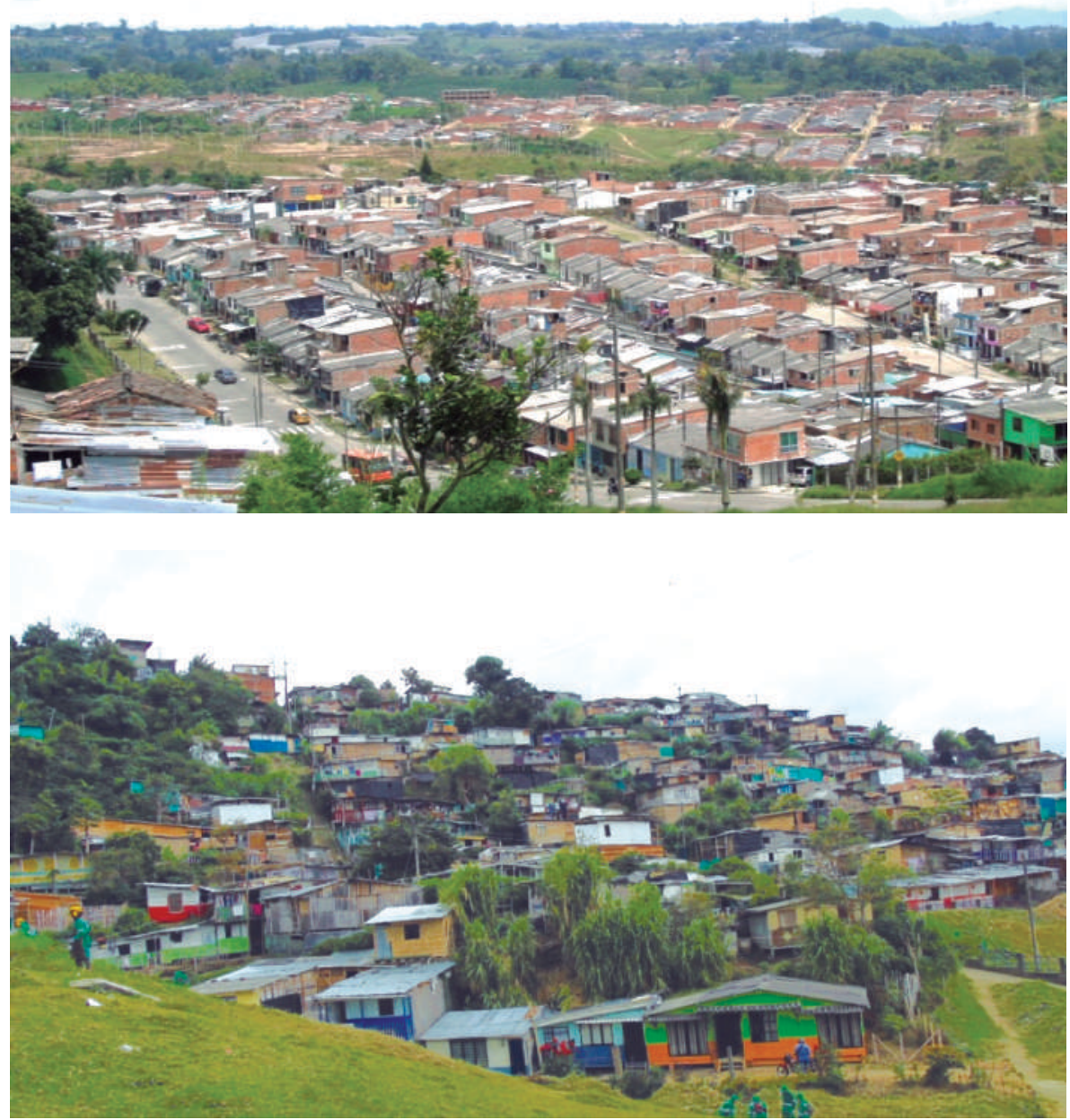

Fuente: imagen y fotografías compartidas por D.2. ${ }^{4}$

Esto muestra la puesta en ejercicio, con sus matices, de lo que fue el modelo de la lepra como elemento particular en la conformación de este espacio. Así, el modelo opera en tanto:

la exclusión de la lepra era una práctica social que implicaba, en principio, una partición rigurosa, una puesta a distancia, una regla

\footnotetext{
${ }^{4}$ Aparece un mapa para ubicar la comuna que se encuentra al extremo derecho marcada por un círculo rojo, mostrando su ubicación en la ciudad. Se suman un par de fotos que muestran los contrastes del barrio las Brisas entre las viviendas de interés social y las invasiones aledañas llamadas el Danubio.
} 
de no contacto entre un individuo (o un grupo de individuos) y otro. Se trataba, por otra parte, de la expulsión de esos individuos hacia un mundo exterior confuso, más allá de las murallas de la ciudad, más allá de los límites de la comunidad. Constitución, por consiguiente, de dos masas ajenas una a la otra [...]. Por último, esta exclusión del leproso, implicaba la descalificación — tal vez no exactamente moral, pero en todo caso si jurídica y política- de los individuos así excluidos y expulsados. En síntesis, se trataba, en efecto de prácticas de exclusión, prácticas de rechazo de marginación, como diríamos hoy. Ahora bien, ésa es la forma en que se describe, y creo que, en la actualidad, la manera en que se ejerce el poder sobre los locos, los enfermos, los criminales, los desviados, los pobres. (Foucault, 2001, p. 51)

Desde esta lógica el modelo funciona sin que el sujeto que se excluya sea un leproso, pero ello no quiere decir que aquel que se expulsa a la periferia de la buena comunidad no sea leído en términos de sujeto peligroso; su aislamiento se convierte en una medida que pasa por el desarrollo, la estética y la seguridad de las ciudades. Tal como reza en los archivos de los diarios de la época del proceso de reubicación entre finales de los 90 y primera década del 2000: "el Concejo de Pereira aprobó el Plan Parcial de Renovación Urbana [...] para transformar las 13 cuadras de inquilinatos, los focos de delincuencia y redinamizar la economía de la región con servicios para más de dos millones de personas" (El Tiempo, 2003, p. 1).

De esta forma esas prácticas discursivas y no discursivas continúan validando el que se lleve al habitante de calle, al desplazado, a las minorías étnicas, al reinsertado, a las personas que habitan en zonas de riesgo, a un mismo lugar como las Brisas y sectores aledaños. Dándole la nominación de sectores vulnerables y peligrosos de la ciudad, haciendo aceptable para muchos que ese sea el lugar donde deben ubicarse. Luego, y es una particularidad, a este sujeto llevado a la periferia a diferencia del leproso no se le sustraen sus derechos puesto que se entiende, a pesar de su alejamiento, parte de lo social. Esto, y su caracterización como proclive al desorden y a la criminalidad, lo hace objetivo de la intervención que irá sobre la seguridad, la población y el espacio físico que habita. Así pues, se configura un campo de intervención en que emerge "un "ambiente" (milieu) artificialmente creado: vivienda con condiciones higiénicas, calles pavimentadas, servicios de transporte urbano, etc." (Castro-Gómez, 2009, p. 123), del cual el modelo de la exclusión del foco peligroso ya es parte en este caso. De esta suerte, los elementos que se plantean pueden recogerse en el siguiente grafo: 


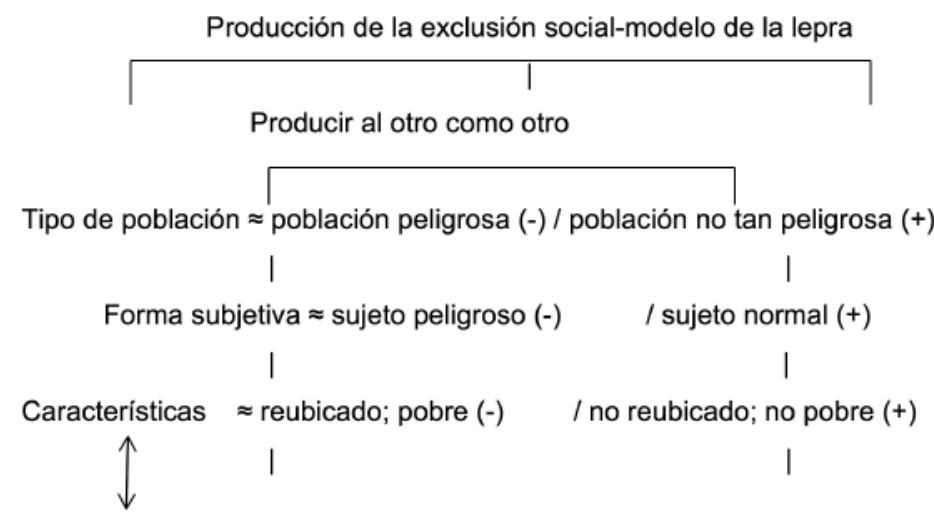

Características $\approx$ reinsertado; desplazado (-) / no reinsertado; no desplazado (+) । Ubicación del riesgo $\approx$ focos de contagio (-) / espacios no contagiados (+)

Aparecen de esta manera inscritas en el territorio un nuevo conjunto de relaciones sociales, espaciales y de gobierno, que podrían nombrarse como territorialización (Mbembe, 2011) o zonificación (Mendiola, 2009), produciendo líneas de demarcación en las ciudades que crean ambientes con categorizaciones jerárquicas de personas, con una gran cantidad de discursos que crean una imaginería social. Alrededor de decires que se multiplican en el Otro de lo Otro, por lo que viene el establecimiento de derechos diferenciales para distintas categorías de personas con objetivos disímiles al interior de un mismo espacio (Mbembe, 2011) donde se da la ocasión de signar al otro entre el estatus de sujeto u objeto según el interés de la estrategia de gobierno de la vida.

\section{Estrategias gubernamentales, nuda vida y bio(tanato)política}

Aparece otro grupo de tecnologías seguritarias que trabajan, fabrican y acondicionan el ambiente donde se espera circulen —según los cálculos de la racionalidad en boga - un tipo particular de gentes, relaciones y estructuras que no sobrepasen la línea de lo tolerable (Foucault, 2006). Es más, puede decirse que en medio de este ambiente producido opera un régimen de regulación muy propio de las sociedades de control que va desde un gobierno de la población en términos biopolíticos hasta un interés de gestionar las conductas y en alguna medida los modos de existencia de los habitantes de este sector. En efecto, se va sobre la especie y se la asume como problema político, la población entra en los cálculos de las estrategias y el gobierno de la vida por lo cual sobre ella se ejercen 
relaciones de poder-saber con la pretensión de gestionar la vida y de hacer vivir (Foucault, 2006); incluido aquel que bajo otros mecanismos se aleja a la periferia. Aparecen campañas de salud sexual y reproductiva con lo que se quiere afectar una natalidad que no sea desmedida, buscando controlar que los pobres no se reproduzcan demasiado y así no crezca mucho en este ítem la carga para el Estado y se mantenga sin desbordarse el foco de peligro. Se generan campañas de salubridad con interés de regular contagios, epidemias o pandemias, así como campañas de promoción y prevención contra el consumo de sustancias psicoactivas con el fin de intervenir morbilidad y mortalidad que puedan afectar y congestionar sistemas de salud y orden público.

A eso se suman otras formas de gobernar la población, técnicas de acción a distancia, que inciden sobre las reglas de juego. En lo que se permite que aquello que rompe la ley y lo visto como socialmente aceptado pueda ser tolerado mientras no quiebre el funcionamiento normal ya naturalizado y soportado por el ambiente diseñado. Aquí se da paso a unas maneras que van más allá de la simple distribución y administración de la vida, lo que considera Mendiola (2009) como la bio(tanato)política, en donde la emergencia del hacer vivir y dejar morir no elimina sino que sustituye y modifica el viejo principio soberano del hacer morir y dejar vivir. Realmente la gestión normalizadora de lo viviente no puede ser ajena a la producción de muerte que caracteriza al poder soberano; lo que en el espacio que se aborda puede evidenciarse desde una aceptación parcial y tácita del homicidio y la violencia, el narcomenudeo, la prostitución, el hacinamiento, la desnutrición infantil y las carencias estructurales del sector. Como lo plantea una de las participantes, y se permite observar en algunos recortes de prensa que guarda,

al barrio y la comuna si llegan algunos programas, pero la verdad la mayoría son asistencialismo o no cumplen procesos amplios y detallados, hacen un par de cosas y ya no sigue la propuesta. Entonces si se ve el abandono, la miseria, muchas problemáticas que el Estado no quiere o no puede solucionar, dejando aquí al amparo del destino, pues a su propia suerte a la gente en muchas ocasiones. La seguridad tampoco es permanente, en ocasiones se ven un par de policías, pero no se arriesgan a estar en un espacio tan complicado, más bien dejan que se las arreglen como puedan. Y en ocasiones, la vista gorda de la ley permite que sus problemas se acaben entre ellos mismos, es decir que las pandillas y bandas criminales se maten entre sí mismas por el dominio de territorio. Es una situación bastante complicada. (P.F.2.) 


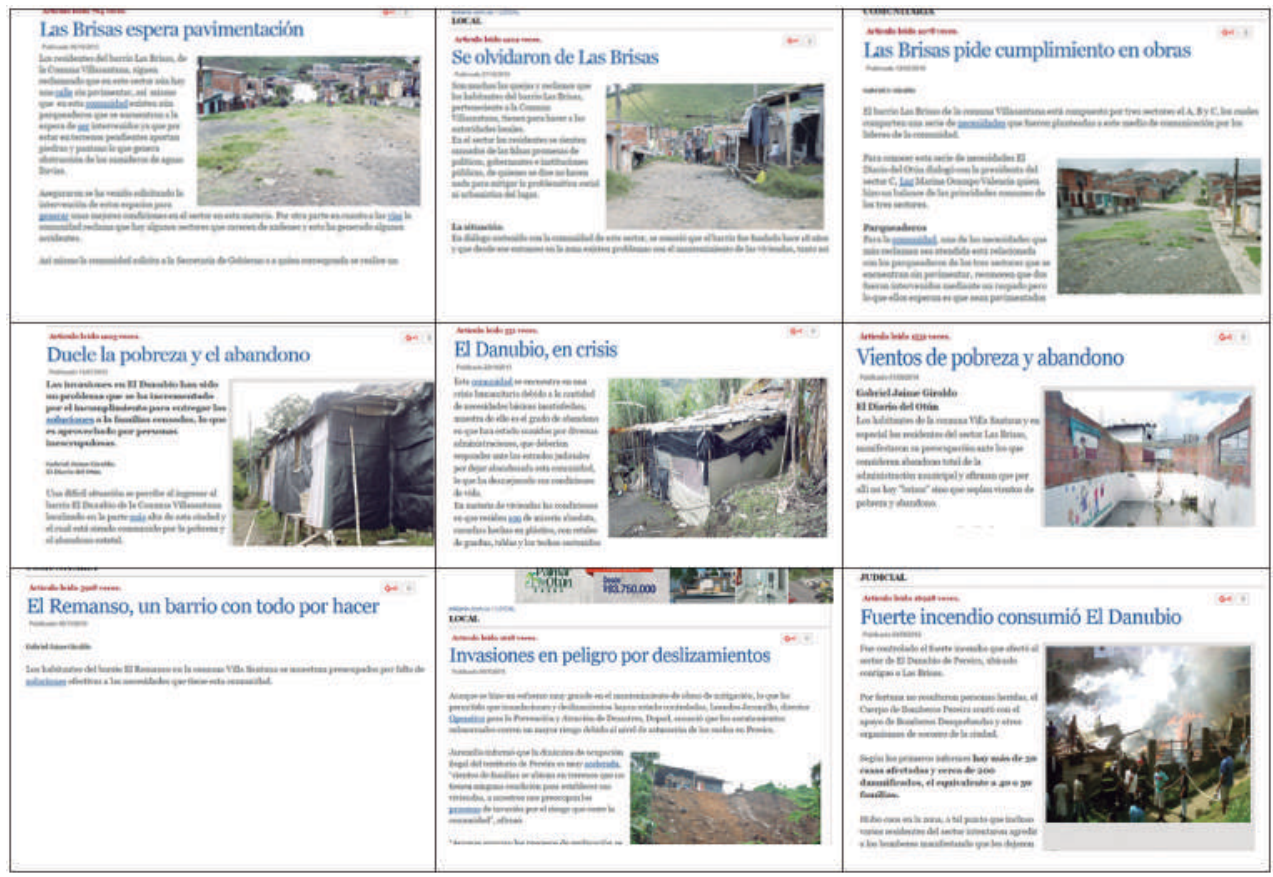

Figura 1. Se recogen titulares que recrean la vida del barrio y sus aledaños en el último lustro. Fuente: archivo compartido por P.F.2.

Entonces la táctica que aparece en medio de estas gramáticas sociales podría nombrarse y apoyarse en el concepto de excepción, que lleva al bando (Agamben, 2013), con lo que es importante afirmar en primer lugar que no hay un Estado de excepción total en este escenario; pues no hay una declaración explícita que permita que se ejerza fuerza - si es necesario desmedida de manera continua - para mantener un tipo particular de orden; no hay un levantamiento completo de un orden legal. Por tanto, en un inicio, más que hacer uso de una extrema y sostenida violencia y un desamparo total, aparece el abandono como un ejercicio de poder estatal que abre sus ojos a medias.

El que ha sido puesto en bando no queda sencillamente fuera de la ley ni es indiferente a esta, sino que es abandonado por ella, es decir, queda expuesto y en peligro en el umbral en que vida y derecho, exterior e interior se confunden. (Agamben, 2013, p. 43-44) 
De esta manera el sujeto abandonado en este caso pierde en alguna medida su lugar de sujeto de derecho, el pacto social muy a menudo cede en medio de estos espacios y para estos sujetos. Un abandono que sirve a ciertos cálculos económicos, políticos y estratégicos de la gubernamentalidad, ya que no requiere un gasto excesivo en términos monetarios y tampoco una confrontación permanente que al mismo tiempo deja que la problemática se mueva en ciertos márgenes de tolerancia. Entonces lo que genera un medio ambiente artificial se entiende desde una articulación de elementos diversos que comprenden los jurídicos pero también prácticas de coacción, de castigo, modelos de gestión, estructuras jerárquicas, aplicación de saberes específicos y por supuesto una articulación de fuerzas muchas de ellas enfrentadas entre sí (Salinas, 2014).

Esta forma particular de excepción tácita y calculada que toma forma en las Brisas y sus barrios aledaños da lugar a un espacio con ciertas características de campo, en clave de Agamben, que no tienen que ver necesariamente con el encierro y que se caracterizan por el abandono y se traducen en la generación de nuda vida (Agamben, 2013). Esta habla de aquella vida que en sus condiciones específicas no puede discernirse, si bien se encuentra en medio de la excepción incluida para que el poder se ejerza sobre ella (su estatuto jurídico, cultural, histórico no es su punto de referencia). Así, para este territorio que se analiza, como se mostró en la cita de la participante y en los titulares de prensa, aparece el sujeto abandonado donde la ley no siempre opera y el Estado no tiene una gran presencia y donde se deja a los sujetos de estos territorios desprotegidos que aparecen entonces en muchas ocasiones como dato biológico, como cifra de mortalidad.

Por tal motivo, hacer que emerja la nuda vida por retiro intermitente de la fuerza estatal genera una excepción que hace que los sujetos se conviertan en homo sacer (Agamben, 2013). Figura del derecho romano que configura un sujeto al cual se le puede matar sin cometer homicidio y que a la vez es insacrificable desde el punto de vista ritual. Es decir que está excluido de la condición jurídica que aplica a los otros hombres, de manera que todos le pueden dar muerte (Salinas, 2014), lo que hace que la nuda vida del homo sacer le abra espacio a las políticas de muerte en medio de las gestiones de la vida. Esta escena intermitente, que aparece y desaparece, por la discontinuidad de la fuerza estatal, en medio del milieu que se analiza, dándole lugar a esa excepción tácita y como se ve no permanente ni tampoco 
cerrada definitivamente, hace que estas maneras específicas lleven a una perdida particular de garantías de derechos consagradas a los ciudadanos. Pues si la Nación habla de isogonía, en tanto que los nacidos iguales, también da entrada a la isonomía como igualdad ciudadana (Álvarez, 2013); en donde los procedimientos para crear la nuda vida y el homo sacer están en ese lugar que, entendido desde la gubernamentalidad, crea una excepción que deja que entre en acción una política de la muerte en medio de la administración de la vida. En ese punto hay unos más iguales que otros en relación a los derechos y a poder conservar su vida o, por lo menos, a que sea protegida con más denuedo. En efecto, nacer en las Brisas y sus aledaños es verse en el punto de poder transitar cualquier día al que solo es nuda vida y que puede ser sacrificado sin que las fuerzas estatales hagan algo por garantizar su derecho a vivir en tanto que igual en la diferencia y libre.

En este orden deideas, y decruce de relaciones de poder muy complejas y finas, siguen mostrándose las características de la gubernamentalidad; esa que opera bajo la bio(tanato)política y es cercana también a lo que codifica la necropolítica de Mbembe (2011), ya que emerge la concepción de la vida del otro como un atentado para otras vidas y como una amenaza mortal - o un peligro absoluto- donde su desaparición biofísica reforzaría el potencial de vida y seguridad de los no peligrosos. Esto genera, en los espacios gubernamentales, una dinámica de cálculo en esa ya conocida relación de costo-beneficio en la que existe también una política de la muerte. Implicando una forma estratégica, pues no simplemente se deja que acontezca de un modo arbitrario, ya que el dejar morir condensa en sí mismo toda una operación que hay que desbrozar para apercibirnos de cómo se produce ese dejar que uno muera no tanto bajo la fórmula de un sujeto dejado a su suerte sino en términos de un sujeto sobre el cual recae un dispositivo que hace que se le deje morir (Mendiola, 2009). Con esto, se le abandona para que tenga lugar el escenario de la nuda vida y con ello la posibilidad del homo sacer. Esto quiere evidenciarse en una recopilación de titulares que vienen desde el 2011 y que muestran estas formas en las que la muerte es algo que aparece de manera recurrente en las Brisas y sus sectores aledaños. 


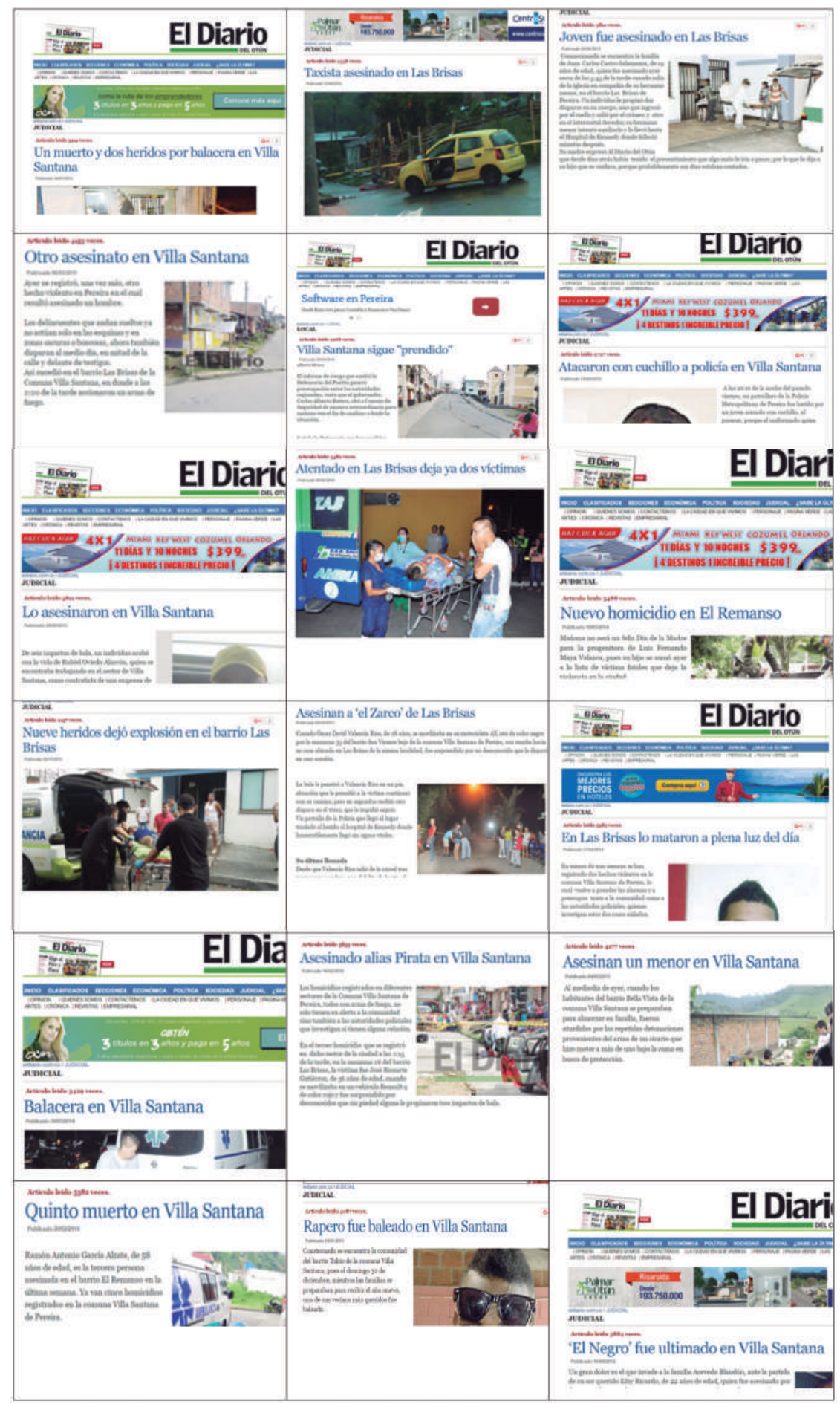




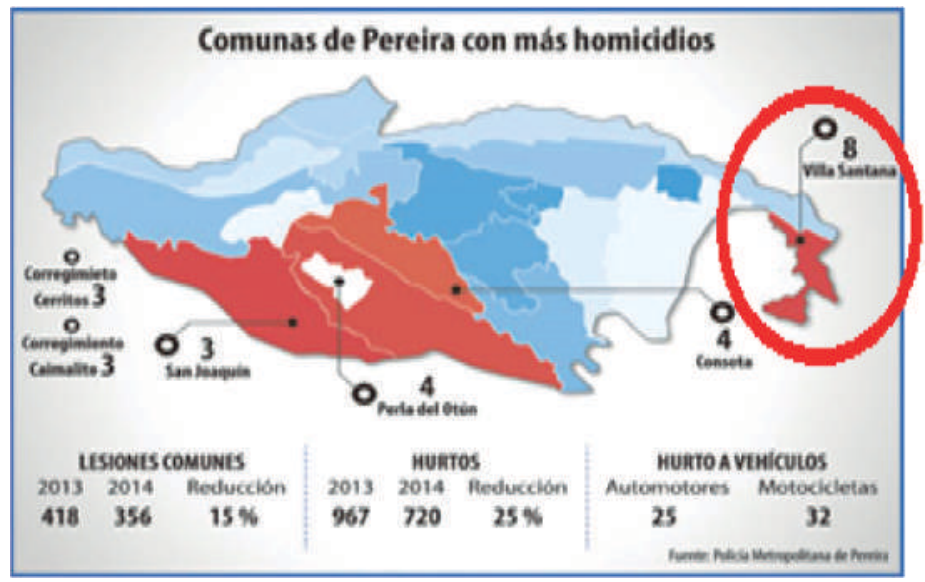

Figura 2. Compilación que muestra la gestión de la muerte en el barrio las Brisas. Fuente: archivo compartido por P.F.2.

Esta compilación muestra la gestión de la muerte, recalcando que no se vuelve sobre un poder soberano sino que la muerte entra en las formas en que se administra y gestiona la vida. El gobierno que se instala desde el capitalismo neoliberal globalizado administra la vida de los pobres y busca que no afecten en gran medida el ámbito de la producción y de la economía. Luego, esta racionalidad económica es productora de pobres. Este régimen de acumulación y monopolio que permite que los sujetos busquen sus propios intereses sin pensar en el bienestar común, dejando este último a la mano invisible de Smith, es fuertemente inequitativo puesto que genera amplias brechas sociales. Un Estado que cada vez se hace más débil y cuya capacidad de invertir en lo social para transformarlo es nimia; aunque tampoco aparece como el interés central, pues el capitalismo neoliberal no quiere acabar con la pobreza debido a que su pretensión es mantenerla regulada. Entonces, aparte de excluir a los pobres como ya se vio, también busca que no se reproduzcan y que los males que les acompañan no se multipliquen. Por tanto:

el dejar morir implica que hay que hacer algo para que se deje morir, que el ordenamiento político-económico de lo social tiene que conformarse de un modo tal que produzca no tanto (o no sólo) la muerte (directa) perseguida por la soberanía cuanto una muerte que irrumpe como desestructuración del modo en que estaba conformada la vida: el dejar morir deviene así un hacer-dejar-morir. (Mendiola, 2009, p. 48) 
En estos "lugares de mala fama", con hombres de "mala fama", son en los que se nace en cualquier parte de cualquier manera y se muere en cualquier parte de cualquier cosa; lugares donde el ejercicio del poder define quién tiene importancia y quién no, quién puede ser fácilmente sustituible y quién no (Mbembe, 2011). Tal modelo podría recogerse en el siguiente grafo, el cual quiere dar cuenta de cómo opera un sistema de reglas de juego partícula en la construcción de este ambiente artificial.

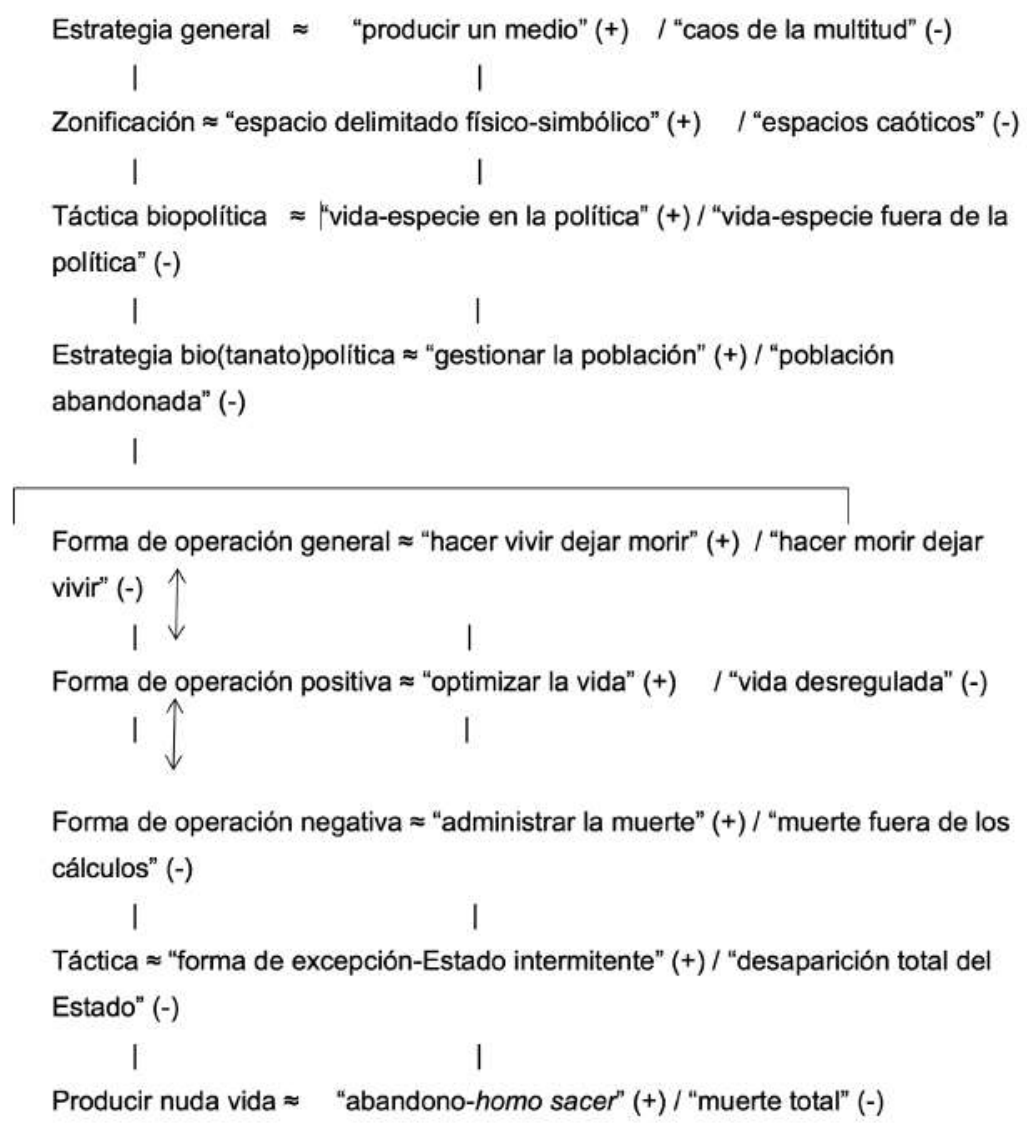

En medio de esta dinámica se visibiliza cómo hay una estrategia gubernamental que opera en la producción de un ambiente artificial; en donde se dan diversas prácticas que van desde la exclusión, la optimización de ciertas formas de vida de la población hasta el abandono en el que emergen maneras de administrar la muerte. Es un ambiente donde las 
formas de gobierno han configurado una serie de sistemas de reglas que exigen del sujeto una cierta actitud para, fundamentalmente, sobrevivir.

\section{Dispositivos de neosoberanía: la paralegalidad desde el narcotráfico}

Adicional a lo planteado aparece con mucha fuerza en esta zona el componente fuera de la ley, el cual va a ser fundamental en la demarcación de las reglas de vida para aquellos que habitan allí; dicho vector va a estar relacionado con formas que rememoran el poder soberano, pero que no le son idénticas. Por ello se habla de una neosoberanía, en clave paralegal (Reguillo, 2010), que da con procesos de desciudadanización (Urteaga y Moreno, 2015) y que configuran el funcionamiento de estas formas delincuenciales.

Hay que considerar que en Pereira y en zonas aledañas existe una banda criminal dedicada al narcotráfico a gran escala y también al narcomenudeo. Esta tiene como nombre la 'Cordillera' y una de sus zonas de presencia es el barrio las Brisas y sus aledaños, en donde se convertirá en uno de los elementos que se inserta de manera dinámica en el orden de las prácticas propias del lugar. Así, estas estructuras delincuenciales aprovechan el abandono en el que se ven sumidos estos escenarios para re-territorializarlos y colonizarlos bajos sus propios objetivos y formas de conducir la vida acorde a sus fines. Ello empieza a evidenciarse en unos de los apartes discursivos de una de las participantes:

la forma que tiene la Cordillera, sobre todo en Las Brisas, es que se convierte en una ley también dentro del lugar, no simplemente son sujetos que expenden y coordinan, sino que se meten mucho más en la vida de la gente, en la vida cotidiana [...] no es que sea normal, lo que pasa es que ellos también han creado un régimen de seguridad. Entonces al crear un régimen de seguridad, le están generando seguridad a las personas que se encuentran allí [...] si, una de sus estrategias es generar seguridad en la comunidad, para que la comunidad tenga aceptación hacia ellos. (P.F.1)

Este testimonio es fundamental y muestra esta forma social que toma parte en medio de la vida del sector. Por tal motivo se produce un grafo que permita representar esta nueva emergencia. 


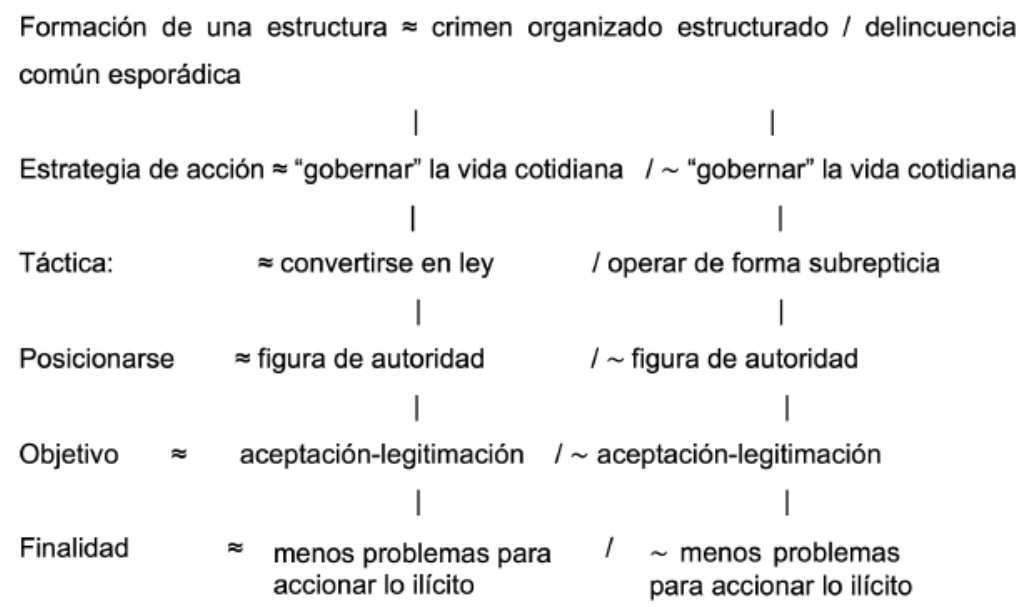

De esta manera estas organizaciones crean un régimen de seguridad y buscan conducir la conducta de los otros en ciertos aspectos. Aunque no logran llegar a marcos biopolíticos y gubernamentales de mayor alcance debido a que no tienen que ver con programas orientados a la natalidad, morbilidad, salubridad, mortalidad y seguridad social de las poblaciones sobre las que ejercen influencia. No obstante, a esta claridad de alcance, puede decirse con Reguillo (2010) que a través de estas formas del narcotráfico se produce en los territorios y sobre las poblaciones un escenario que rompe drásticamente con lo legal,

una nueva fase en las violencias vinculadas al narco [...]. Las violencias no se ubican en un más allá, circunscribible a un espacio otro, a una heterotopía salvaje y lejana vinculada a la barbarie por contraposición a la civilización; ellas están aquí, ahora, presentes en un espacio complejo que no admite las distinciones de las viejas dicotomías y, de otro lado, es indudable que su comportamiento y recurrencia anuncia, cuando menos, la falacia de pensarlas como brotes excepcionales que sacudirían de vez en vez el paisaje armónico y pacífico de una pretendida normalidad "normal". (p. 35)

En la línea de este argumento, las formas narcotraficantes, para la ciudad de Pereira y zonas aledañas como el Norte del Valle del Cauca, han pasado a ser desde hace un buen tiempo parte de la trama social. No son elementos esporádicos o que se den en selvas o montañas, sino que aparecen encarnados en la cotidianidad de la ciudad con más presencia en ciertos sectores (uno de ellos la comuna Villa Santana y sobre todo las Brisas y sus barrios contiguos). Estas fuerzas controlan los territorios, en muchas 
de sus características, y son capaces de operar a espaldas o en complicidad con la misma ley más allá de lo legal. Donde ellos son parte, juez y verdugo en una "trilogía que lejos de desafiar las normas jurídicas, las leyes, en tanto ellas no son parámetro o unidad de medida, funda sus propios marcos de operación y sentido" (Reguillo, 2010, p. 35). Esto va más allá de la anomalía al crear nuevos regímenes de gobierno que se basan en un tipo de relaciones saber-poder no estatales, pero operativas y vigentes, con lo cual marcan de manera definitiva las formas de hacer de sus habitantes.

La legalidad representa el escenario del contrato social, del pacto social que se sustenta en una serie de derechos y deberes específicos sostenidos desde lo jurídico y la estructura estatal. Mientras que aquello que se sitúa fuera de tal compromiso y quiebra sus reglas aparece como el escenario de lo ilegal; como el más allá de la ley que huye, se esconde, opera a hurtadillas, de manera fugaz y en las sombras. Aquí habría que seguir a Reguillo (2010) cuando alude que los modus operandi del poder que despliegan los narcotraficantes más contemporáneos pertenecen a un tercer espacio:

en este contexto resulta difícil afirmar que las violencias desatadas por el narco-poder y el crimen organizado, puedan ser inscritas en el afuera de la ilegalidad. Este análisis es a todas luces simplista e insuficiente. Por ello propongo abrir un tercer espacio analítico: la paralegalidad, que emerge justo en la zona fronteriza abierta por las violencias, generando no un orden ilegal, sino un orden paralelo que genera sus propios códigos, normas y rituales que al ignorar olímpicamente a las instituciones y al contrato social, se constituye paradójicamente en un desafío mayor que la ilegalidad. (p. 36)

La paralegalidad, en este contexto, es encarnada en la banda criminal 'Cordillera'. Dicha banda implementa un nuevo tipo de régimen de seguridad, adaptado a una forma particular de normas que no están bajo algún tipo de contrato social particular, aquí no hay ciudadanos. Puede decirse que con las prácticas de gobierno que implementa esta estructura criminal se da una reemergencia de aquello que Foucault (2002) llama el poder soberano, que para estas condiciones aparecería con una suerte de neosoberanía que desciudadaniza.

En este sentido puedemanifestarsequeel poder deestas organizaciones tiene similitudes con el poder soberano, pues hace énfasis inicialmente en uno o algunos sujetos sobre los que recae una posibilidad concentrada de ejercicio del poder. Aunque en este caso no existe un rey bajo un régimen teocrático. Esa fuerza, igual que en la soberanía, va sobre las tierras donde su dominio puede permitir riqueza en razón a la rentabilidad y resguardo 
de sus negocios. Existe también un parecido en la relación asimétrica entre lo que toman de las gentes y lo que les dan, en el caso del soberano hay por lo menos una inversión mínima. En este sentido la inversión sobre el territorio y sus gentes no aparece, salvo la excepción de la estrategia de la seguridad. Sin embargo, sobre todo, y allí su gran cercanía, es un régimen de poder que también se sustenta en hacer morir y dejar vivir. Así lo plantean un par de participantes:

el tipo de castigo que le dan a la gente depende de la gravedad del error. Mire, está la más común que es, como se dice coloquialmente, cascarles, darles una pela impresionante entre cuatro o cinco, contra uno. La otra es que los hacen ir, inmediatamente, "tiene de plazo tantos días, o tantas horas, para que se desaparezca del barrio". Si no, ya optan por las otras medidas; lo matan, ahí está la otra. (P.F.1)

Algo que pasó en estos días y fue algo muy fuerte, y era que [...] muchachos, como dicen ellos, dañinos. Y parece ser que a un muchacho se lo llevaron a Tokio, abajo en la cañada y lo mataron a golpes. Eso fue muy fuerte hermano, fue muy fuerte que lo hubieran matado a golpes... (P.M.1)

En consecuencia, se muestra de manera clara ese privilegio característico del poder soberano de vida y muerte: hacer morir y dejar vivir (Foucault, 2002). En este caso dicho poder se ejerce cuando alguien expone o pone en riesgo la existencia y la autoridad de aquellos que pueden hacer, por su posición, que se desplieguen las relaciones de fuerza y aún más de violencia. Con base en ello estos nuevos súbditos que deben obediencia irrestricta a este neo-poder soberano sin rey, pero con capos y jefes, llegan a levantarse contra sus intereses y ejercen "sobre su vida un poder directo: a título de castigo lo matará" (Foucault, 2002, p. 163).

Esta forma de relación de poder se funda en las armas y el miedo puesto que esta neosoberanía, que no está basada en un contrato social ni legitimada en un supuesto designio divino como en otrora, es frágil y puede romperse y caer en desuso; lo que requiere por parte de estos neosoberanos de la paralegalidad un suplemento de amenaza, violencia y terror. Triada esta que va finalmente sobre el cuerpo por medio del suplicio ya no ejercido por el potro, la rueda o sus similares sino a través de la golpiza contundente hasta la muerte: forma brutal de ejercer la violencia o de otros tipos de tortura. Una violencia que, al decir de Segato (2004), sería utilitaria y para este caso no expresiva; pues opera desde una economía del poder que no pretende ejercer el poder únicamente para hacer gala de sus fuerzas y su capacidad destructora. Más bien muestran su capacidad de dominio 
y sometimiento del cuerpo y la vida de aquellos que se encuentran bajo su espacio de seguridad a partir de un "fin instrumental", pero sistemático y brutal cuando se ejerce para hacer que el orden que se impone no se fisure. Se ejecuta en las circunstancias de quiebre de los códigos y normativas impuestas, yendo desde las advertencias hasta la muerte.

Así, como se ha venido postulando, emergen otras formas de desciudadanización que continúan haciendo que la vida siga estando expuesta; pues aparece un retiro de derechos civiles y políticos no solo debido al accionar de la paralegalidad, sino también debido a las actuaciones del Estado y la fuerza pública sobre las organizaciones delincuenciales. Aunque hay un cierto margen de tolerancia, esto no quiere decir que en ningún momento no se den y se vayan a dar operaciones de choque para no permitir un desfase de estas maneras criminógenas; lo cual hace que aquellos que están vinculados a la Cordillera entren en la posición de objetivos militares legítimos para las fuerzas públicas estatales.

Con base en ello, según la Directiva 003 sobre crímenes de guerra de la Fiscalía General de la Nación, se les considera como combatientes y es legítimo que sobre ellos se use el principio de necesidad militar; a este tenor:

en su sentido genérico el término "combatiente" hace referencia a las personas que, por formar parte de las fuerzas armadas y de los grupos armados irregulares, o toman parte en las hostilidades, no gozan de las protecciones contra los ataques asignadas a los civiles. $(2015$, p. 7$)$

[...] la necesidad militar que una parte, sujeta a las leyes de la guerra, aplique cualquier cantidad y tipo de fuerza para someter militarmente a la parte contraria, con el menor gasto posible de tiempo, vida y dinero [...]. Permite la destrucción de la vida de los enemigos armados y de otras personas cuya destrucción sea incidentalmente inevitable. (2015, p. 17)

Lo anterior, tiene dos fuertes implicaciones. Lo primero es que aquellos que soportan la estructura operativa de la organización son en su mayoría personas del sector, por lo tanto se convierten en blancos legítimos. Se lleva a cabo un claro proceso de desciudadanización, que juega bajo el modelo de Estado de excepción, en donde los sujetos son sacados del espacio de la vida política de una comunidad resguardada por derechos y se les sitúa en el lugar de la nuda vida; pues sus derechos son suspendidos convirtiéndolos en homo sacer, al cual es válido darle muerte y no recibir castigo por ello (tal como es la situación de las fuerzas militares regulares). El ejercicio de criminalización lleva a la desciudadanización y convierte al otro en uno al que no hay que proteger ni garantizar su vida, es un sujeto 
asesinable (Urteaga y Moreno, 2015) que está en el espacio del afuera y a la vez adentro de lo social normativo por la excepción que permite el uso de la fuerza letal; en donde "la nuda vida, a la que el hombre ha sido reducido, no exige nada ni se adecúa a nada; es ella misma la única norma, es absolutamente inmanente" (Agamben, 2002, p. 71). Lo segundo es que esta excepción no solo afecta a los cuerpos que son vaciados de derecho por la misma ley (Urteaga y Moreno, 2015), en términos de criminalización, sino que también pone en situación de excepción a aquellos que están cercanos los cuales su destrucción incidental puede ser inevitable.

\section{Conclusiones}

Se puede plantear que una ciudad intermedia latinoamericana, como lo es Pereira, muestra —al igual que muchas otras ciudades- grandes contrastes que pasan por medidas biopolíticas y gubernamentales en la construcción de un medio artificial que no tiene la misma consistencia en todos los espacios, poblaciones y subjetividades que allí habitan.

En este sentido las gramáticas sociales analizadas exponen un espacio de hondas y complejas problemáticas sociales que desde su inicio en un movimiento táctico-biopolítico de exclusión fue diseñado y signado con la marca de lo Otro, de lo peligroso. Aquí el abandono estatal hace que, esta zonificación que quiere alejar a estas "gentes problemáticas, desordenadas y violentas", devenga en un territorio hostil para la vida donde se nace de cualquier manera y se puede morir de cualquier forma lejos de la sociedad calificada como moralmente buena. Sumada a esta estrategia neoliberal sobre la pobreza de un hacer-dejar-morir, que entra en los cálculos de sostenimiento de un sistema que sabe que esto ocurre y más que reconocerlo lo posibilita, aparece la fuerza bruta de la neosoberanía vehiculada por la paralegalidad que emerge con las formas del narcotráfico y el microtráfico que se arraigan y despliegan como un tipo de gobierno de la vida y las conductas de la gente del sector bajo los preceptos del hacer morir-dejar vivir. Todo esto confluye en una suerte de Estado de excepción tácito e intermitente, lo que se traduce en la falta de garantías de derechos no solo de vida digna —en términos de cubrimiento de las necesidades básicassino en la falta de garantías sobre la vida; haciendo que emerja la nuda vida, en tanto sujetos que devienen simple dato biológico, estando al borde de la comunidad política que implica garantías constitucionales. Esto lleva a que la condición de homo sacer, que puede ser muerto sin una protección sociojurídica, sea una regularidad en medio de estas mortíferas gramáticas de vida. 
Así pues, para dar una síntesis de estos sistemas de reglas de juegos sociales que se instalan en las Brisas y sus aledaños, vale la pena la siguiente matriz:

\section{EJE BIOS-ZOE}

\section{Pacto social}

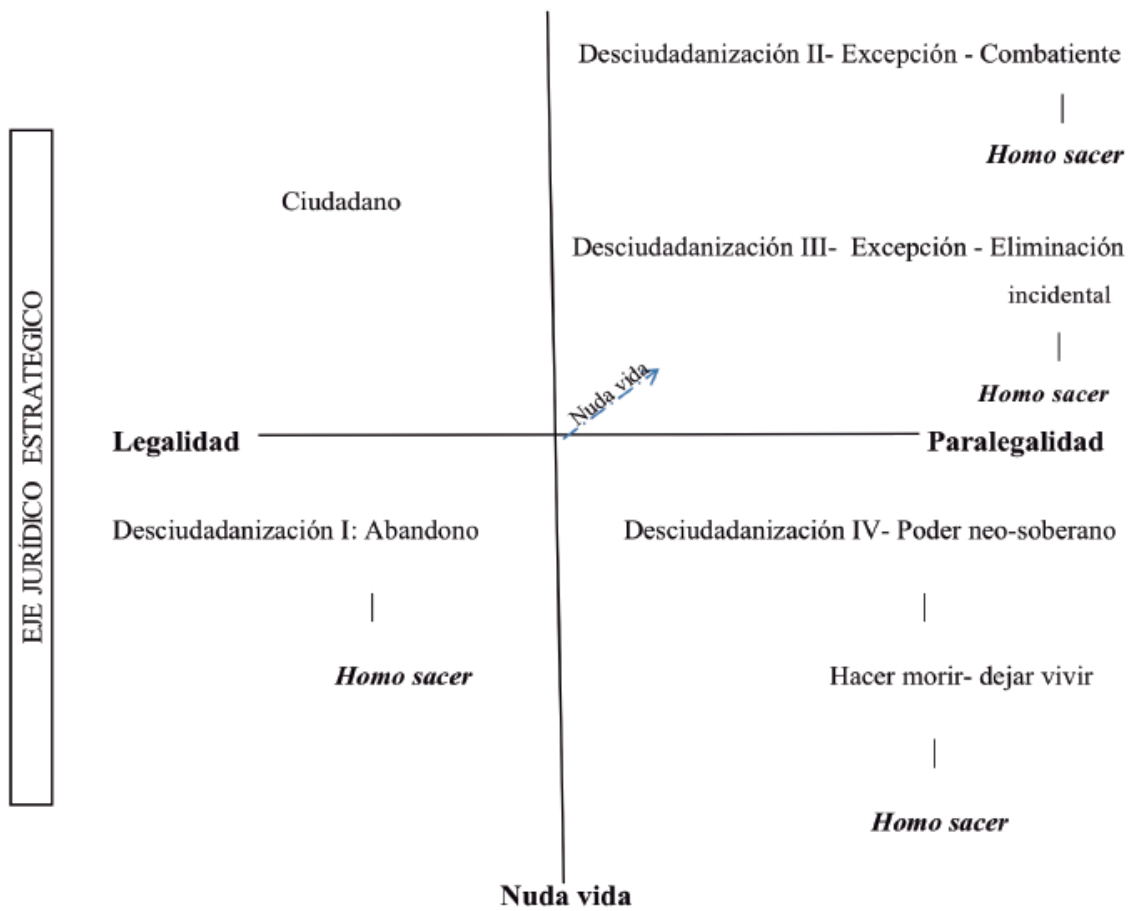

En esta matriz se recrea esa gramática social atravesada por la muerte, una gramática de muerte que hace que para los habitantes de este sector emerja una condición cuatro veces mortífera de peligro que da cabida a una desciudadanización cuádruple que logra que el devenir homo sacer tenga un alto margen de probabilidad. Puede identificarse, de este modo, en primer término, un proceso de desciudadanización en el que los sujetos pueden morir por el abandono del Estado en medio de un ambiente artificial que es propicio para que esto pueda suceder. En segundo lugar se puede ser reclutado o buscar el reclutamiento de la banda criminal y así devenir combatiente, lo que convierte a tales sujetos en blancos legítimos del poder estatal. Como tercer aspecto está el ser asesinado por no responder a los códigos de conducta impuestos por la paralegalidad que implanta la banda criminal la 'Cordillera' 
en el sector. Finalmente pueden llegar a caer muertos de manera incidental en medio de la confrontación entre la fuerza pública y dicha banda.

Esto no quiere decir que en medio de estos escenarios sociales y sus gramáticas las personas estén totalmente gobernadas, más bien este artículo muestra algunas de las regularidades en las que se traduce cierto ejercicio del poder. Sin embargo hay que decir que desde la comunidad en sus formas organizadas (los jóvenes, los niños y algunos docentes y personas que concurren con su trabajo en el sector) se generan otro tipo de posibilidades para la vida, una vida más allá del estigma y la exclusión que tiene la capacidad de romper con la violencia y con la muerte gestando unos espacios y formas alternos.

\section{Referencias bibliográficas}

Agamben, G. (2002). Lo que queda de Auschwitz. El archivo y el testigo. Homo sacer III. Valencia, España: Pre-textos.

Agamben, G. (2013). Homo sacer: el poder soberano y nuda vida. Valencia, España: Pre-textos.

Álvarez, J. (2013). El último Foucault: voluntad de verdad y subjetividad. Madrid, España: Editorial Biblioteca Nueva.

Bonilla-Castro, E. y Rodríguez, P. (2005). Más allá del dilema de los métodos: la investigación en ciencias sociales. Bogotá, Colombia: Grupo Editorial Norma.

Castro-Gómez, S. (2009). Disciplina, biopolítica y noopolítica en Mauricio Lazzarato. En I. Mendiola. Rastros y rostros de la biopolítica. Barcelona, España: Anthropos.

Castro-Gómez, S. (2010). Historia de la gubernamentalidad: razón de Estado, liberalismo y neoliberalismo en Michel Foucault. Bogotá, Colombia: Siglo del Hombre Editores.

Deleuze, G. (1995). Conversaciones 1972-1990. Valencia, España: Pre-Textos.

Delgado, J. y Gutiérrez, J. (1999). Métodos y técnicas cualitativas de investigación en ciencias sociales. Madrid, España: Editorial Síntesis S.A.

El Tiempo. (2003). En marcha, ciudad Victoria. Recuperado de http://www.eltiempo.com/ archivo/documento/MAM-1045812.

Foucault, M. (1985). La imposible prisión. Barcelona, España: Editorial Anagrama.

Foucault, M. (1988). El sujeto y el poder. En H. Dreyfus y P. Rabinow. Michel Foucault: más allá del estructuralismo y la hermenéutica. Ciudad de México, México: Universidad Nacional Autónoma de México.

Foucault, M. (1994). Microfísica del poder. Barcelona, España: Planeta DeAgostini.

Foucault, M. (1999). Obras esenciales. Volumen I: entre filosofía y literatura. Barcelona, España: Editorial Paidós.

Foucault, M. (2001). Los anormales. Curso del College de France, 1974-1975. Ciudad de México, México: Fondo de Cultura Económica.

Foucault, M. (2002). El orden del discurso. Barcelona, España: Tusquets.

Foucault, M. (2003). El yo minimalista y otras conversaciones. Buenos Aires, Argentina: Editorial la Marca.

Foucault, M. (2003). Historia de la sexualidad. Volumen II: el uso de los placeres. Buenos Aires, Argentina: Siglo XXI Editores.

Foucault, M. (2003). Sobre la Ilustración. Madrid, España: Editoriales Tecnos.

Foucault, M. (2006). Defender la sociedad. Ciudad de México, México: Fondo de Cultura Económica. 
Foucault, M. (2006). Seguridad, territorio y población. Buenos Aires, Argentina: Fondo de Cultura Económica.

Foucault, M. (2008). El nacimiento de la biopolítica. Buenos Aires, Argentina: Fondo de Cultura Económica.

Foucault, M. (2008). La hermenéutica del sujeto. Buenos Aires, Argentina: Fondo de Cultura Económica.

Foucault, M. (2009). El gobierno de sí y de los otros. Buenos Aires, Argentina: Fondo de Cultura Económica.

Grinberg, S. (2008). Educación y poder en el siglo XXI. Gubernamentalidad y pedagogía en las sociedades de gerenciamiento. Buenos Aires, Argentina: Editorial Miño y Dávila.

Hiernaux, J. (2008). Análisis estructural de contenido y de modelos culturales. Aplicación a materiales voluminosos. En H. Suárez. El sentido y el método: sociología de la cultura y análisis de contenido. Ciudad de México, México: El Colegio de Michoacán.

Hiernaux, J. et Ganty, A. (1977). Sociologie des groupes chrétiens contemporains, systéms symboliques, insertion sociale et mobilization affective. Louvain, Belgium: La Neuve.

Jaramillo, Ó.A. (2017). Prácticas artísticas y modos de subjetivación en experiencias de la música y la danza teatro en la ciudad de Pereira (tesis de posgrado). Universidad de Manizales y CINDE, Manizales, Colombia.

Fiscalía General de la Nación. (2015). La Directiva 003 sobre crímenes de guerra. Bogotá, Colombia: Fiscalía General de la Nación.

Lazzarato, M. (2007). La filosofía de la diferencia y el pensamiento menor. Bogotá, Colombia: Editorial Universidad Central, IESCO y Fundación Comunidad.

Mbembe, A. (2011). Necropolítica. Seguido de sobre el gobierno privado indirecto. Tenerife, España: Melusina.

Mendiola, I. (2009). Rastros y rostros de la biopolítica. Barcelona, España: Anthropos.

Reguillo, R. (2010). La in-visibilidad resguardada: violencia(s) y gestión de la paralegalidad en la era del colapso. Diálogos Transdisciplinarios en la Sociedad de la Información, 1, 33-43.

Sáenz, J. (2014). Artes de vida, gobierno y contraconductas en las prácticas de sí. Bogotá, Colombia: CES.

Saldarriaga, Ó. (2003). Del oficio de maestro: prácticas y teorías de la pedagogía moderna en Colombia. Bogotá, Colombia: Editorial Magisterio.

Saldarriaga, Ó. (2008). Lineamientos curriculares en ciencias sociales. Análisis estructural de sus sistemas de sentido. En H. Suárez. El sentido y el método: sociología de la cultura y análisis de contenido. Ciudad de México, México: El Colegio de Michoacán.

Saldarriaga, J. (2015). De la socialización política a los procesos de subjetivación posibilidades y límites de las escuelas críticas en la configuración de procesos de subjetivación de jóvenes escolares (tesis de posgrado). Universidad de Manizales y CINDE, Manizales, Colombia.

Salinas, A. (2014). La semántica biopolítica. Foucault y sus recepciones. Viña del Mar, Chile: CENALTES.

Segato, R. (2004). La escritura en el cuerpo de las mujeres asesinadas en Ciudad Juárez. Labrys: Estudos Feministas, 6, 35-45.

Suárez, H. (2008). El sentido y el método: sociología de la cultura y análisis de contenido. Ciudad de México, México: El Colegio de Michoacán.

Strauss, A. y Corbin, J. (2002). Bases de la investigación cualitativa. Técnicas y procedimientos para desarrollar la teoría fundamentada. Medellín, Colombia: Universidad de Antioquía.

Urteaga, M. y Moreno, H. (2015). Corrupción e impunidad versus justicia y derecho en México. En J. Valenzuela. Juvenicidio. Ayotzinapa y las vidas precarias en América Latina y España. Barcelona, España: NED ediciones.

Valles, M. (1999). Técnicas cualitativas de investigación social: reflexión metodológica y práctica profesional. Madrid, España: Editorial Síntesis S.A.

Veyne, P. (1984). Cómo se escribe la historia. Foucault revoluciona la historia. Madrid, España: Alianza editorial. 